\title{
FMH-Gutachterstelle - eine Dienstleistung für alle Landesteile unter einem Dach
}

\author{
Fehler kommen überall vor, auch in der ärztlichen Tätigkeit. Genau um solche \\ kümmert sich die FMH-Gutachterstelle. Sie ist eine Anlaufstelle für Patienten, \\ die ärztliche Fehler vermuten, die zu einem erheblichen Gesundheitsschaden \\ geführt haben, und wenn zwischen Patient und Haftpflichtversicherer keine \\ Einigung möglich ist. Seit 7. Juli 2008 ist die FMH-Gutachterstelle zentral in \\ Bern angesiedelt; ihr Angebot richtet sich auch weiterhin an die gesamte \\ Schweiz.
}

\begin{abstract}
Büros neu in Bern
Bisher hatte die FMH-Gutachterstelle sowohl ein Büro in Lausanne als auch eines in Bern mit je einer Person. Um die Zusammenarbeit zu vereinfachen, entschied man, die bisherigen Büros zusammenzulegen. Die Wahl des Standorts fiel auf Bern, weil sich dort das Generalsekretariat der FMH samt Rechtsdienst befindet. Susanne Friedli wird weiterhin für die Dossiers der Deutschschweiz zuständig sein. Brigitte Mottet hat sich gegen einen Wechsel nach Bern entschieden. Ab August 2008 betreut neu Eric Vuithier die Dossiers der Romandie. Die rechtliche Unterstützung erfolgt weiterhin durch den Rechts-
\end{abstract}

Deutschsprachige Schweiz und Tessin Aussergerichtliche Gutachterstelle der FMH Postfach 6159, 3001 Bern

Tel. 03138058 10, Fax 0313805819

Susanne Friedli, Tel. 0313805812

Lucia Rabia, Fürsprecherin (juristische Unterstützung) dienst der FMH, Nathalie Favre für die Romandie und Lucia Rabia für die Deutschschweiz und das Tessin.

\section{Angebot bleibt gleich}

Ausser der Postanschrift und der Telefonnummer ändert sich nichts. Persönliche Vorsprachen bei der Gutachterstelle sind nach wie vor nicht möglich. Das Verfahren wird schriftlich abgewickelt und Auskünfte sowie Beratungen erfolgen telefonisch oder schriftlich. Auch nach der Schliessung des Büros in Lausanne sind die Dienstleistungen für die Romandie unverändert dieselben.
Französischsprachige Schweiz Bureau d'expertises extrajudiciaires de la FMH, Case postale 6159, 3001 Berne tél. 03138058 10, fax 0313805819 Eric Vuithier, tél. 0313805814 (dès le 11.8.2008) Nathalie Favre, licenciée en droit (soutien juridique) 